Fecha de recepción: 09-10-2017

Fecha de aceptación: 23-01-2018

Link para este artículo: http://dx.doi.org/10.14198/ALEUA.2018.29-30.07

Puede citar este artículo como:

Ríos Carratalá, Juan A., «La senda iluminada (1949), de Fernando Vizcaíno Casas», Anales de Literatura

Española, n. ${ }^{\circ}$ 29-30 (2018), pp. 161-173.

\title{
LA SENDA ILUMINADA (1949), DE FERNANDO VIZCAÍNO CASAS
}

\author{
JuAN A. RÍOS CARRATALÁ \\ Universidad de Alicante
}

\section{Resumen}

Fernando Vizcaíno Casas es un autor con múltiples facetas, aunque solo es recordado por sus éxitos editoriales durante la Transición. El teatro fue una de sus constantes biográficas menos conocidas. Nunca la reivindicó un autor tan satisfecho consigo mismo, pero tuvo premios, estrenos polémicos y la satisfacción de que La senda iluminada (1949) le permitiera participar en el TEU.

Palabras clave: Fernando Vizcaíno Casas, teatro universitario, comedia de la felicidad.

\begin{abstract}
Fernando Vizcaíno Casas is an author with multiple facets, although he was only recognised by his successfull leading articles during the Spanish Transition. Drama was one of less known biographical attitudes. It as never claimed by himself, despite of being a proud author. Anyway, he won prizes, controversial premieres and the satisfaction that La senda iluminada (1949) allowed him to participate in TEU.
\end{abstract}

Keywords: Fernando Vizcaíno Casas, university drama, happiness comedy

La imagen pública de los autores populares suele ser el fruto de una simplificación o una reducción de sus trayectorias. Frente a la diversificación y la posible complejidad de las mismas, los medios de comunicación y las propias editoriales optan por seleccionar las facetas o los rasgos que han permitido a estos autores acceder a la popularidad y/o al prestigio. Así no cabe sorprenderse de que el recuerdo del polifacético Fernando Vizcaíno Casas (Valencia, 1926Madrid, 2003) haya quedado asociado a las novelas publicadas durante la 
Transición, cuando el valenciano se convirtió en un fenómeno sociológico por sus reiterados y espectaculares éxitos de ventas. Las multitudinarias presentaciones de sus novelas, las largas colas para conseguir un ejemplar firmado, las adaptaciones cinematográficas dirigidas por Rafael Gil con buenos resultados de taquilla y otras circunstancias coetáneas completan las dimensiones de una realidad que, por su relevancia sociológica y hasta política, debiera salir del olvido al que ha sido sometida por los investigadores universitarios.

La temprana nostalgia del franquismo -omnipresente en estas obras de Fernando Vizcaíno Casas escritas deprisa, desde mediados de los años setenta, y con notable oportunismo-supone una incómoda evidencia para numerosos historiadores. Como tal, ha sido obviada o descalificada de manera somera hasta el punto de que, en ensayos dedicados a la cultura durante la Transición, ni siquiera se menciona a un polígrafo capaz de vender más de cuatro millones de ejemplares y copar con varios de sus títulos las listas de ventas. El absurdo de esta exclusión es notable desde el punto de vista histórico y permite comprender hasta qué punto el relato oficial de la Transición se ha convertido en una de las ficciones colectivas más arraigadas, incluso en el ámbito universitario.

Algunos de los mecanismos capaces de convertir un período histórico tan reciente en una ficción con aceptación popular me han ocupado en libros como Usted puede ser feliz. La felicidad en la cultura del franquismo (2013), Quinquis, maderos y picoletos. Memoria y ficción (2014) y La mirada del documental. Memoria e imposturas (2014). La complejidad del tema requiere nuevos estudios y en Suelas gastadas. Periodistas y escritores en tiempos de cambio (2017) he dedicado un apartado (pp. 187-204) a la trayectoria de un Fernando Vizcaíno Casas cuya obra resulta casi desconocida para la investigación académica. Tal y como es frecuente en estos casos, la confirmación de las sospechas previas acerca de sus trabajos se compagina con la sorpresa de descubrir facetas o circunstancias del autor que apenas han trascendido. La labor como dramaturgo del valenciano durante tres décadas es un buen ejemplo, puesto que permite confirmar su imagen habitual gracias a las oportunistas y nostálgicas obras representadas en los cafés-teatro de Madrid durante la Transición y descubrir que, muchos años antes, el heredero de una acomodada familia de Valencia fue un joven universitario del SEU con inquietudes teatrales.

Fernando Vizcaíno Casas estaba orgulloso de su trayectoria de triunfador en varias facetas -abogado, escritor, empresario, padre, esposo...- y escribió sus memorias en tres volúmenes donde muestra una satisfacción blindada a la crítica o la duda. La reivindicación de sí mismo en un tono coloquial, anecdótico y directo es compatible con una selectiva e interesada nostalgia, que el valenciano compartió con sus numerosos lectores, siempre agradecidos 
por haberles reconciliado con el pasado franquista cuando el presente era un tiempo de incertidumbres o cambios. Esa nostalgia de las novelas, las colaboraciones en prensa y las memorias se vincula con una época: los años cuarenta y cincuenta, principalmente. También con la juventud de una generación que no protagonizó la Guerra Civil, pero comulgó con la Victoria sin albergar apenas motivos para la duda o la inquietud.

En ese marco de la memoria satisfecha, cualquier experiencia, incluso las menos exitosas en su balance, puede ser un motivo de interés nostálgico. Así, Fernando Vizcaíno Casas también dejó constancia de su faceta teatral iniciada durante la etapa de estudiante de Derecho en la Universidad de Valencia. El análisis de su trayectoria en el mundo de las letras desde que, en 1946, empezara a publicar entrevistas a personajes populares para la etapa inicial de Triunfo, artículos acerca de los más variados temas en Las Provincias y reseñas cinematográficas en Acción, un semanario valenciano del SEU, permite comprender algunas de las razones de su nostalgia durante la Transición. Fernando Vizcaíno Casas es un representante, casi un arquetipo, del franquismo sociológico. El polifacético autor nunca ocupó cargos de relieve ni ejerció en la esfera pública $\mathrm{u}$ oficial de la dictadura. La circunstancia queda reiterada en las memorias para desvincularse del poder político de la misma. No obstante, su trayectoria solo se comprende desde ese franquismo sociológico que, por haber triunfado en lo social y económico con la ayuda de unas privilegiadas y exclusivas condiciones durante décadas, conservaba numerosos motivos de agradecimiento una vez muerto el general Franco. La nostalgia en su caso responde a un comprensible fundamento, que Fernando Vizcaíno Casas intenta extrapolar al conjunto de la población, como si su suerte de joven acomodado y vencedor hubiera sido la tónica general del país.

Niñas... ¡al salón! (1976), Y al tercer año... resucitó (1978), ¡Viva Franco! (Con perdón) (1980)... Los títulos de las publicaciones de Fernando Vizcaíno Casas despejan cualquier duda acerca del contenido. Las novelas se sucedieron con un reiterado éxito de ventas hasta mediados de los años ochenta, gracias a un público fiel, maduro e identificado con un autor apenas pendiente de la calidad literaria de unas obras de difícil adscripción genérica. La operación nostalgia representaba una reivindicación del pasado individual o colectivo de estos lectores durante la dictadura. El objetivo era proporcionarles un buen relato para afrontar sin autocrítica ni complejos una Transición que se pretendía controlar y hegemonizar, aparte de cerrar herméticamente a cualquier petición de responsabilidades. El olfato comercial de Fernando Vizcaíno Casas percibió esta demanda de un amplio colectivo desde principios de los setenta y, al 
iniciarse el proceso democrático, la consiguiente campaña fue orquestada con la ayuda de la editorial Planeta y buena parte de los periódicos de la época.

El resultado de la operación nostalgia tuvo un indudable calado. Al menos, en ese franquismo sociológico tan presente en la cultura de masas durante los primeros años de la democracia como poco estudiado, sobre todo a través de sus creaciones en la novela, el teatro y el cine, que en la actualidad a veces producen sonrojo y hasta incredulidad. Superadas ambas reacciones de la mirada retrospectiva, doy cuenta de algunos ejemplos en Suelas gastadas (2017: 187204), donde también incluyo referencias a los inicios literarios y periodísticos de un Fernando Vizcaíno Casas capaz de mostrarse en los escenarios como un joven del SEU con «inquietudes».

La vocación teatral de Fernando Vizcaíno Casas fue una constante de su trayectoria desde la etapa universitaria a mediados de los cuarenta hasta la Transición, cuando en el marco de los café-teatro el valenciano rivalizó en vulgaridad con Alfonso Paso y estrenó algunas obras tan lamentables como oportunistas. Al menos, a tenor de los títulos y las indicaciones dadas en las memorias: Streaking-show, Historias del tierno galán, el amo del ayuntamiento, ¡Ay Felipe de mi IVA!... También fueron lamentables y reiterados sus problemas con las compañías -incumplimientos de los contratos, impagos de los derechos de autor, falsas promesas...-, así como las desilusiones por la dificultad a la hora de estrenar las comedias en Madrid. Aparte de la colaboración con Guillermo Sautier Casaseca en la adaptación teatral de sus seriales, el hito en la capital y como autor profesional solo lo consiguió Fernando Vizcaíno Casas en 1965 con Psicoanálisis de una boda. La tradicional comedia de figurón fue puesta en escena bajo la dirección de Miguel Narros en el Teatro Maravillas por la compañía de Don Jaime de Mora y Aragón. El distinguido golfo por entonces estaba en el apogeo de su popularidad en España gracias a la boda de su hermana Fabiola con el rey Balduino de Bélgica y, dispuesto a no pagar por falta de costumbre, era un tipo capaz de espantar mediante su picaresca a un baqueteado autor y abogado como Fernando Vizcaíno Casas. La historia completa de estas representaciones aparece en Un franquismo con franquistas, actualmente en prensa.

El comediógrafo valenciano escribió con oficio una comedia de encargo y mucha carpintería para el lucimiento del cabeza de cartel. Gracias a esta disposición de un autor al servicio de la empresa, «El Fabiolo» interpreta el papel de Paco - «un fresco la mar de simpaticón»-junto a un reparto donde se combina la juventud de María Luisa Merlo y Terele Pávez con la veteranía de Guadalupe Muñoz Sampedro. El público del Maravillas acudió a ver a Jaime de Mora y Aragón haciendo de sí mismo y en directo como personaje popular que 
era. La experiencia del aristócrata sin títulos se repitió en numerosos cameos de las comedias cinematográficas de los años sesenta. El tal Paco permite a «Don Jaime» 0 «Jimmy» responder al tipo sin salirse de los cauces más trillados de una comedia de figurón con el correspondiente enredo y la sorpresa final. Antes de este estreno en el Maravillas, y a pesar de las facilidades dadas por un comediógrafo dispuesto a amoldarse a las exigencias comerciales, cada intento de sacar adelante una comedia fue una sucesión de problemas con los empresarios teatrales. Las dificultades y la falta de seriedad agotaron la paciencia de un autor que, por entonces, ya triunfaba como abogado. Fernando Vizcaíno Casas esperaba su momento en la faceta que le haría popular a raíz de la muerte de su admirado Francisco Franco.

Los inicios del universitario Fernando Vizcaíno Casas en la literatura dramática discurrieron por caminos ajenos a ese teatro comercial y se vieron jalonados por una sucesión de premios. Al margen de la comedia que nos ocupa, en diciembre de 1950 el valenciano obtuvo el Premio Calderón de la Barca en su primera convocatoria con El baile de los muñecos (Triunfo, 14-III1951). Poco después, Los derrotados (1950) fue galardonada por la Agrupación de Noveles y El escultor de sus sueños (1952) recibió un premio teatral otorgado por la Diputación Provincial de Valencia. Los tres textos permanecieron inéditos, no se estrenaron como tantas veces sucediera con los de otros jóvenes dramaturgos y, en sus memorias, el autor apenas aporta información sobre su temática u orientación. Fernando Vizcaíno Casas era consciente de que su teatro suponía un tema menor para los lectores que le seguían como triunfador desde mediados de los setenta.

La senda de estos reconocimientos oficiales u oficiosos, a menudo ajenos a los géneros triunfantes en los escenarios profesionales, estaba expedita para Fernando Vizcaíno Casas. Al menos desde que el estudiante de tercero de Derecho y entusiasta miembro del SEU optara al premio del Certamen Teatral Universitario Hispanoamericano, convocado en diciembre de 1948 por la Tertulia Literaria del Colegio Mayor Pedro Cerbuna, de Zaragoza. La convocatoria de los colegiales también incluía una categoría de narrativa cuyo galardón recayó en una obra de Diego Moreno, un novelista que trabajaría después en Córdoba como periodista. El premio de poesía correspondió a la joven María del Pilar Martínez. La agraciada poetisa con el tiempo dejaría los versos para ocuparse de sus clases en un centro escolar y de sus ocho hijos. El jurado formado por Francisco Ynduráin, Alberto Blecua y otros catedráticos de la época otorgó el premio de teatro a Fernando Vizcaíno Casas por su comedia La senda iluminada, que sería estrenada poco después por la compañía Talía en el Teatro Principal de Zaragoza el domingo 27 de marzo de 1949. Al parecer con 
éxito de taquilla por la presencia de amigos, familiares y estudiantes. Tanto fue así, que los beneficios del trabajo de estos jóvenes aficionados permitieron al citado colegio organizar el primer viaje de fin de carrera e interfacultativo (VV. AA., 1996). La actividad teatral todavía estaba en disposición de subvencionar el ocio estudiantil.

El debutante en las tareas de comediógrafo quedó contento, puesto que los organizadores le invitaron a ver la representación, le dieron un premio de dos mil pesetas gracias a la generosidad del gobernador civil y, además, Fernando Vizcaíno Casas concedió un par de entrevistas en la prensa local con motivo del estreno. La tertulia literaria fundada por Jesús López Medel -un futuro registrador de la propiedad que por entonces vestía la reglamentaria camisa azul- quedó satisfecha, al igual que el colegio mayor Pedro Cerbuna. El centro adscrito a la Universidad de Zaragoza por entonces organizaba actos culturales siempre acordes con su acendrado catolicismo y editaba cada año la revista Cerbuna, en cuyas cartas al director algún atrevido colegial llegó a reclamar la presencia de crucifijos en todas las dependencias. La sobriedad presupuestaria, según el peticionario, solo debía manifestarse en los gastos superfluos, concepto en el que no cabía imaginar la inclusión de los crucifijos.

En ese marco del nacionalcatolicismo y en una sesión matinal para poder alquilar el local de Zaragoza triunfó La senda iluminada, que el 29 de diciembre de 1949 también se representó en el Infanta Beatriz. En esta ocasión, la puesta en escena corrió a cargo de la sección nacional del TEU y estuvo bajo la dirección del incansable Modesto Higueras con una escenografía bocetada por Pepe Caballero y realizada por Sancho Lobo. La representación fue reseñada por el camarada Marco Valerio en Juventud. Semanario de combate del SEU, más adelante Semanario de las Juventudes Españolas, el 5 de enero de 1950. Los intérpretes de aquella sesión única en Madrid fueron las señoritas Cecilia Ferraz, Amanda Méndez, $\mathrm{M}^{\mathrm{a}}$. Adela Buscher y Ofelia González, correspondiendo los papeles masculinos a «los señores Montero, Grau, Puy, Fuentes y Rodao» (ABC, 30-XII-1949). Los jóvenes intérpretes recibieron el cálido aplauso del público, así como el autor, al que se le auguraba un gran porvenir en los escenarios. Dos años después, Fernando Vizcaíno Casas escribió en compañía de Francisco Ramos de Castro el libreto del juguete cómico-lírico titulado El tercer hombro, con música del maestro Guerrero. La obra llegaría a las cien representaciones tras su estreno en el Albeniz (ABC, 23-II-1951). Las sendas iluminadas fortalecían la fe, pero apenas daban dinero y el valenciano estaba dispuesto a cultivar cualquier género para triunfar en el teatro comercial.

Fernando Vizcaíno Casas no solo tuvo su primer reconocimiento como dramaturgo con La senda iluminada, sino que demostró a su padre la posibilidad 
de triunfar lejos de Paraguas Vizcaíno, la próspera empresa familiar de la que el estudiante de Derecho habría debido ser heredero universal. La inclinación por las letras y el estudio del hijo supuso un gran disgusto en la familia de acomodados comerciantes, según se cuenta en las memorias del autor. La circunstancia autobiográfica quedó grabada en la memoria y alentaría la redacción de El sucesor, una comedia estrenada en el Gran Teatro Falla, de Cádiz, el 15 de noviembre de 1963. Ambientada en el Madrid de 1946, el año de los inicios literarios del comediógrafo, Fernando Vizcaíno Casas no duda en incluir referencias a Anita Ekberg, los bikinis de Torremolinos, las películas de Marisol y los goles de Di Stéfano... El rigor histórico del resucitador de Franco nunca fue su punto fuerte, pero la relación de don Antonio Moreno, propietario de la Casa Moreno y orgulloso de llevar un guardapolvo en su oficina, y su hijo Antoñito, músico de inquebrantable vocación, trasluce el conflicto habido en el domicilio de los Vizcaíno cuando el sucesor decidió dedicarse a las letras.

Al menos, el premio obtenido por La senda iluminada aliviaría el recelo de un padre tan real como estricto. El señor Vizcaíno nunca terminó de perdonar al comediógrafo desde que el joven abandonara las labores de un representante de paraguas, y otros accesorios de la moda, para iniciar en Valencia unos estudios universitarios culminados en Madrid. El propio Fernando Vizcaíno Casas, dispuesto a convencer al padre-empresario de la bondad de sus intenciones, le dedicó la edición de La senda iluminada, impresa en Valencia con cargo a las dos mil pesetas que le concediera el gobernador civil de Zaragoza. Antoñito, su alter ego en El sucesor, hace lo mismo con una sinfonía compuesta en Roma tras su marcha a Italia en contra del parecer paterno. El gesto de amor filial precipita la reconciliación del desenlace, a diferencia de lo sucedido en la familia del comediógrafo. La realidad se confundió con el deseo. En cualquier caso y gracias a este detalle de buen hijo, conservamos el texto de La senda iluminada en las bibliotecas públicas, a diferencia de lo sucedido con el resto de los premiados o representados. Salvo El fiscal -una comedia acerca de los problemas de conciencia del protagonista, que fue estrenada en el Teatro Lope de Vega, de Sevilla, el 13 de octubre de 1956- y El sucesor, estos textos anteriores a su fama como novelista nunca fueron editados. Tampoco los rescató del olvido un autor amargado por su escasa fortuna en los escenarios. El triunfador, a la hora de escribir sus memorias, relega las facetas menos exitosas o las presenta como una víctima de la injusticia.

La reseña del estreno de La senda iluminada en Madrid informa de que, según la nota explicativa del programa, «el autor ha querido dar a su invención escénica una solución cristiana y ortodoxa, basada en el camino salvador de la fe» (ABC, 30-XII-1949). El aviso de Fernando Vizcaíno Casas era una forma 
de curarse en salud, pues ningún espectador habría podido dudar al respecto. De hecho, el camarada Marco Valerio resalta la ortodoxia de la obra: «Muy elogiable la idea que guio a Fernando Vizcaíno Casas para escribir su comedia y ofrecer una solución definitiva, por cristiana, a la natural angustia que oprime hoy día a la Humanidad después de los últimos trágicos acontecimientos, que han colocado al hombre en un aparente callejón sin salida. La tesis de La senda iluminada no puede ser atacada por ningún lado, pues únicamente un sentido espiritualista - evangélico- de la vida puede iluminar las tinieblas actuales y llevar a los últimos rincones de la razón la luz de la Verdad eterna» (Juventud, $\left.n^{\circ} 321,5-\mathrm{I}-1950\right)$.

La senda iluminada se desarrolla en «época actual», pero «en un país europeo», que bien podría ser la Alemania de la posguerra por algunas referencias y la lógica de los tiempos. En ese marco vagamente sugerido, Fernando Vizcaíno Casas presenta la Escuela de Vocaciones Anormales, al frente de la cual se encuentra el enigmático doctor Kyre. Las paredes del centro están adornadas con retratos de Juana la Loca, el Quijote y otros dementes famosos, al tiempo que los alumnos ejercen de Napoleón, César o los socorridos fantasmas, cuyas pretensiones de asustar siempre se saldan con el fracaso para dar la nota de humor en la comedia. Según el citado doctor, los pacientes o alumnos de la Escuela de Vocaciones Anormales se liberaron de la vida porque quieren ser napoleones, césares, romeos, gardenias..., «con lo que mueren un poco, pero sin escapar para siempre de la vida real» (p. 12). El objetivo del doctor -uno más entre los muchos que, con distintos grados de extravagancia, poblaron los escenarios de la posguerra- se concreta en la felicidad de los alumnos de esa escuela, porque «su locura es mucho más digna que su desesperada sensatez de antes» (p. 17).

El doctor Kyre carece del ingenio de Enrique Jardiel Poncela y no es el inventor de alguna socorrida píldora para rejuvenecer hasta volver a la infancia o vivir sin dormir. El humor del absurdo no aparece en La senda iluminada, pero el protagonista se suma a la larga serie de doctores imposibles del teatro o el cine de la época y se impone «el deber de ayudar a los desesperados de la vida» (p. 21). El propósito pasa por ofrecerles una alternativa irreal al estar basada en una falsa locura. No obstante, resulta satisfactoria porque les permite olvidar un pasado donde los alumnos convivían con quienes mataban, destruían, intrigaban... La oferta del doctor a un nuevo miembro de la escuela pasa por una disyuntiva esclarecedora: «Elija usted. Aquí, un mundo absurdo, loco, en el que se cree y se sueña. Allá, la vida, atrozmente racional, descaradamente realista» (p. 39). Vista así la disyuntiva, la respuesta del alumnado es quedarse porque, al llegar a la escuela, los pacientes «estaban enfermos por el odio, 
por la desesperación, por el desengaño. Querían suicidarse, acabar de una. Les asustaba el mundo, temían a sus semejantes. Eran piltrafas humanas, sin porvenir, sin ambición. Llegaban pidiendo paz» (p. 50). El panorama de las «vocaciones anormales» era tremendo y el doctor Kyre les proporcionaba esa paz, «aunque para ello fuera preciso sacrificar su razón» (p. 50).

La situación en la Escuela de Vocaciones Anormales cambia en el segundo acto cuando irrumpen las jóvenes Emma y Helen, que con su natural belleza y simpatía se oponen a las teorías del doctor Kyre: «Olvidar no puede ser nunca una solución. Cerrar los ojos a la realidad, enloquecer voluntariamente para no luchar contra ella, tampoco» (p. 54). Emma todavía es más incisiva cuando deja de hablar con el doctor y lanza al respetable una pregunta retórica: « ¿Acaso el cariño, la fe en Dios, no les serían más útiles que ese torpe empeño de cegar el sentido común?» (p. 56). Y, una vez obtenido el asentimiento del público, la joven cristiana arremete contra Kyre: «Es usted más desdichado que todos estos pobres locos. Estando aparentemente sano, tiene enferma el alma, doctor. Le come el desengaño, la desilusión. Y su única preocupación consiste en reunir adeptos, en incrementar sus filas de desesperados para consolarse con el mal ajeno, intentando olvidar el propio» (p. 73). El doctor Kyre se tambalea ante esta argumentación de Emma, que culmina su labor apostólica con la fuerza de una catequista: «no cabe construir un mundo a la medida de nuestro deseo, porque Dios nos da la razón para las alegrías y para las tristezas, nos da el corazón para gozar y para sufrir; y es tan inmoral matar la razón voluntariamente como cortar nuestra propia vida» (p. 84).

La tesis de la comedia ya está sentada, las posibles dudas han sido disipadas y solo cabe rematarla con el reconocimiento de su error por parte del doctor Kyre, que era hombre equivocado sin caer en la categoría de los malvados. Gracias a este ejemplar cambio de postura, el joven Emil -nunca estuvo verdaderamente loco, como corresponde a la carpintería teatral- puede afirmar que los alumnos salen de «un abismo oscuro» y les acoge «una senda luminosa»: «Vamos con los ojos abiertos, luego de tanta ceguera» (p. 94). Todos los personajes se encuentran en condiciones de ser iluminados por la verdad. La clave del título de la comedia la acabamos de comprender, si cabían dudas al respecto, cuando uno de ellos afirma que dicha senda representa «el amor, la fe, la esperanza, dando luz a todo» (p. 95). La retórica es de manual y se trata de una luz que procede directamente de la Biblia, cuya lectura a partir de entonces será la exclusiva recomendación terapéutica dada por el doctor Kyre, pues sus páginas nos orientan por la senda iluminada que conduce a «la única felicidad» (p. 97). La referencia a la Biblia tal vez extrañara a los espectadores, tan habituados a los textos del nacionalcatolicismo como poco duchos en los 
pasajes bíblicos. Algunos pensarían en una singularidad del joven autor, pero debemos recordar que la acción dramática se desarrolla en «un país europeo», concepto que por entonces excluía a la autárquica España.

El origen de la comedia de la felicidad se remonta al período anterior a la Guerra Civil, pero en los escenarios españoles tuvo su momento de esplendor durante aquellos años del franquismo más ortodoxo. El tema ya lo abordé en Usted puede ser feliz (págs. 85-112) a partir de las obras de Edgar Neville, a cuyas aportaciones podríamos añadir las de otros comediógrafos (Miguel Mihura, Víctor Ruiz Iriarte, José López Rubio...) interesados en dar una respuesta escénica a la consigna de felicidad impuesta por la dictadura. Tampoco entraremos ahora en las motivaciones de esta paradoja que articula el conjunto del citado ensayo. Baste con señalar que el joven Fernando Vizcaíno Casas parece consciente de «la oscuridad» en la que podría encontrarse la población europea tras la II Guerra Mundial, de la necesidad de olvidar un pasado inmediato. En las antípodas del Roberto Rossellini de Germania anno zero (1947), el valenciano concibe como respuesta la fantasía de la escuela del doctor Kyre, pronto sustituida por la ortodoxia de quienes siguen los preceptos de la Biblia por ser la garantía de «la única felicidad». Semejante reduccionismo al gusto de los censores apenas guarda relación con las coetáneas comedias de una felicidad mucho más laica y gozosa, aunque a menudo ingenua e inmotivada.

Fernando Vizcaíno Casas leería con interés la reseña en $A B C$ de la puesta en escena de Modesto Higueras. En la misma, se relaciona La senda iluminada con Prohibido suicidarse en primavera (1937), de Alejandro Casona, y El puente de los suicidas (1944), de Víctor Ruiz Iriarte, un autor que también debía al jefe nacional del TEU la posibilidad de haber debutado en su faceta teatral con el estreno de Un día de gloria en 1944. El exilio del primero es ignorado en la reseña, así como que la citada comedia hubiera sido estrenada en Méjico por la compañía de Josefina Díaz y Manuel Collado (Teatro Abreu, 12-VI-1937). Aunque editada en Buenos Aires por Losada desde 1941 y puesta en escena varias veces en Argentina, Prohibido suicidarse en primavera resultaría de difícil acceso para un joven autor que, a tenor de sus memorias, a finales de los años cuarenta no parece interesado en conocer las andanzas de quienes habían partido para el exilio.

En cualquier caso, la relación de La senda iluminada con la comedia de Alejandro Casona parte de que en la segunda también encontramos un peculiar doctor, Roda, dispuesto a acoger en el Hogar del Suicida a quienes por su desesperación parecen abocados a dar voluntariamente el último paso. Al final, la obra del exiliado es una candorosa y retórica defensa de la voluntad de vivir porque la vida no solo es un derecho, sino un deber, como se repite 
en varias ocasiones para evitar las dudas del público. El Hogar del Suicida con sus variadas y acogedoras ofertas para un suicidio ejecutado dignamente carece de sentido. Así lo reconoce su responsable. Y los protagonistas en el desenlace comparten el tono aleccionador y espiritualista de Alejandro Casona: deciden afrontar la vida. Lo hacen sin refugiarse en la ayuda de quienes con dicho hogar pretenden combatir una ola de suicidios cuyas motivaciones -como es habitual en el dramaturgo asturiano- parecen responder a la metafísica o a la más convencional tradición teatral. La diferencia básica entre Alejandro Casona y Fernando Vizcaíno Casas radica en la calidad del lenguaje dramático y en la concreción del desenlace. Mientras que en el primero es fruto de una reivindicación de la voluntad de vivir por encima de cualquier pena u obstáculo, en el segundo la misma se vincula únicamente a la lectura de la Biblia, a la vía religiosa como salida de la oscuridad o la ceguera.

La reseña de $A B C$ señala la relación directa de la obra de Fernando Vizcaíno Casas con la comedia de Alejandro Casona y la concreta en la obra citada. Sin embargo, el valenciano asumió con cierto orgullo esa prestigiosa relación, pero nunca citó Prohibido suicidarse en primavera como fuente de La senda iluminada. La edición de 1941 publicada en Buenos Aires podría haber llegado a sus manos y cabe suponer que le hubiera servido de inspiración, incluso en varios detalles argumentales y recursos teatrales donde el paralelismo entre ambas comedias es bastante notable, hasta llamativo. También todo pudiera ser fruto de una coincidencia donde no hubiera premeditación por parte del autor. En cualquier caso, sorprende que una obra del exilio y otra del futuro resucitador del general Franco muestren un significativo paralelismo en su voluntad aleccionadora para afrontar la vida, aunque Alejandro Casona la base en un confuso panteísmo y Fernando Vizcaíno Casas, para despejar dudas, la concrete en la Biblia como fuente de la única felicidad posible.

La relación de La senda iluminada con la también citada comedia de Víctor Ruiz Iriarte, que constituyó un fracaso en su estreno, es mucho menor. Ambas obras comparten un rasgo frecuente en el teatro español de la época: la abstracción de las coordenadas espacio-temporales para evitar cualquier referencia a la realidad y argumentar así la tesis desde una perspectiva exclusivamente dramática, sin ataduras con las circunstancias concretas. La consiguiente indefinición de los referentes se repite, aunque en el caso de Victor Ruiz Iriarte la comedia se escribe con una voluntad poética ausente en Fernando Vizcaíno Casas, cuyo desenlace por la vía religiosa desentona entre unos comediógrafos que hablando de la felicidad solían huir de cualquier concreción, incluida la bíblica. 
El planteamiento de la comedia de Fernando Vizcaíno Casas gustaría en el marco del teatro universitario de finales de los años cuarenta, cuando apenas cabía imaginar que las inquietudes de los autores se desviaran de la ortodoxia. Fernando Vizcaíno Casas era en 1949 un joven satisfecho de vivir bajo el franquismo, nunca habría planteado una obra conflictiva o pesimista y, por supuesto, su única pretensión pasaba por un teatro universitario como vía de acceso al profesional. De hecho, en sus memorias apenas habla del primero, ni siquiera explica su posible relación con el grupo de Modesto Higueras y se lamenta a menudo de que los escenarios copados por las compañías profesionales nunca le acogieron en las debidas condiciones. La suerte le resultó esquiva, a pesar de que Fernando Vizcaíno Casas dominaba la técnica teatral y mantenía relaciones personales con el mundillo de la farándula por su faceta de abogado defensor de numerosos intérpretes. Su empeño de profesional resultó baldío, a diferencia de lo sucedido con esa realidad paralela de los premios, que aportaban reconocimiento o prestigio sin que los aplausos de una sesión única y matinal se tradujeran en derechos de autor. La consecuencia fue la desilusión del propio Fernando Vizcaíno Casas, que después de aleccionar al público del TEU sobre «la única felicidad» estuvo dispuesto a cultivar todos los géneros con posibilidades comerciales, hasta los juguetes cómicos y líricos. La predisposición fue notable, pero nunca vio cuajar un proyecto con continuidad que le permitiera acceder a la restringida nómina de los dramaturgos profesionales.

La historia del comediógrafo valenciano desde las «inquietudes» de la posguerra hasta la zafiedad del café-teatro durante la Transición se repite en otros casos e incluso resulta un tanto tópica y previsible. Los ejemplos cinematográficos de Rafael Gil -adaptador de las novelas de Fernando Vizcaíno Casas durante los años setenta y ochenta-, José Luis Sáenz de Heredia e Ignacio F. Iquino podrían servir en el mismo sentido. El teatro universitario escrito por jóvenes del SEU abunda en promesas nunca cumplidas por imperativos de la realidad o falta de voluntad de los protagonistas. Si recordamos aquí el caso del valenciano es porque evidencia que, para los jóvenes de orden como Fernando Vizcaíno Casas, el régimen de la Victoria tenía a su disposición unas salidas destinadas a satisfacer las inquietudes creativas que pudieran albergar. Todo estaba debidamente encauzado para los grupos que mantenían una relación más o menos clientelar con la dictadura. Las memorias del autor así lo prueban provocando la consiguiente satisfacción del triunfador, que con el tiempo formaría parte de los motivos capaces de justificar la nostalgia manifestada en sus novelas durante la Transición. Al fin y al cabo, en una mentalidad apegada al refranero y el sentido común como fuentes del razonar, era de bien nacidos ser agradecidos. Fernando Vizcaíno Casas lo tendría en cuenta, aunque la 
«senda iluminada» pronto quedara desdibujada como una prolongación de los ejercicios espirituales tan habituales entre los universitarios de la época. La pasajera locura del doctor Kyre solo era un aviso para los caminantes que, sintiéndose vencedores, estaban seguros de seguir la senda iluminada

\section{Bibliografía citada}

Casona, Alejandro (1960), Teatro, Buenos Aires, Losada.

GÓMEZ GARCíA, Manuel (2006), Modesto Higueras: el maestro y la asamblea, Madrid, Gráficas Caro.

Ríos Carratalá, Juan A. (2013), Usted puede ser feliz, Barcelona, Ariel.

VV.AA. (1996), Las memorias del Cerbuna, Zaragoza, Colegio Mayor Pedro Cerbuna [véase la web de la institución académica].

VizCAíno CASAS, Fernando (1949), La senda iluminada. Comedia en tres actos, Valencia, Tip. Levante.

- (1958), El fiscal, Madrid, Alfil.

- (1964), El sucesor, Madrid, Alfil.

- (1965), Psicoanálisis de una boda, Madrid, Alfil.

- (2002), Los pasos contados. Memorias, III, Barcelona, Planeta. 